\title{
Penentuan Kadar Tembaga (Cu) dalam Sampel Batuan Mineral
}

\author{
M.Anugrah Rizky Pambudi, Suprapto, S.Si., M.Sc., Ph.D \\ Departemen Kimia, Fakultas Ilmu Alam, Institut Teknologi Sepuluh Nopember (ITS) \\ e-mail: suprapto@chem.its.ac.id
}

\begin{abstract}
Abstrak-Telah dilakukan penentuan kadar tembaga $(\mathrm{Cu})$ dalam batuan mineral. Batuan mineral ini dianalisis kandungan tembaga (Cu didalamnya menggunakan instrumen Flame Atomic Absorption Spectrophotometry (FAAS). Sampel dilakukan preparasi dengan metode destruksi basah menggunakan larutan $\mathrm{HNO}_{3}$ pekat. Dalam analisis kadar tembaga $(\mathrm{Cu})$, dibuat kurva standar untuk mengetahui hubungan antara konsentrasi larutan dengan nilai absorbansi sehingga konsentrasi sampel dapat ditentukan. Larutan standar 2 ppm, 4 ppm, 6 ppm, 8 ppm, dan 10 ppm dibuat dengan metode pengenceran bertingkat larutan stock yang dibuat dari padatan $\mathrm{Cu}\left(\mathrm{NO}_{3}\right)_{2} .3 \mathrm{H}_{2} \mathrm{O}$. Regresi kurva kalibrasi yang didapat sebesar 0,9995. Berdasarkan hasil perhitungan, diperoleh kadar $\mathrm{Cu}$ dalam sampel batuan sebesar 2,189 ppm atau $21,66 \%$.
\end{abstract}

Kata Kunci-Konsentrasi, logam Cu, Absorbansi, Spektrofotometer AAS.

\section{PENDAHULUAN}

B ATU merupakan suatu zat yang padat, keras, dan tahan lama. Karakteristik dari beberapa jenis batu bervariasi bergantung kepada kondisi dan cara pembentukannya. Batuan tersusun atas mineral-mineral. Mineral dibagi dalam kelompok-kelompok menurut unsur-unsur yang menyusunnya. Mineral-mineral yang tersusun dari satu unsur saja disebut unsur-unsur asli [1]. Mineral yang terbentuk akan ditentukan oleh elemen-elemen yang tersedia dan melalui berbagai jenis temperatur dan tekanan yang berbeda yang merata selama waktu kristal terjadi. Misalnya, jika logam seperti $\mathrm{Cu}, \mathrm{Zn}, \mathrm{Pb}$, dan $\mathrm{Fe}$ terdapat bersama sulfur, sulfida-sulfida dari elemen ini akan terbentuk seperti $\mathrm{FeS}_{2}$, $\mathrm{CuFeS}_{2}, \mathrm{PbS}$, dan $\mathrm{ZnS}$. Di sisi lain, jika metal seperti $\mathrm{Cu}$, $\mathrm{Pb}, \mathrm{Zn}$, dan $\mathrm{Fe}$ terdapat bersama dengan karbon dan oksigen, kemudian karbonat kemungkinan akan terbentuk seperti $\mathrm{FeCO}_{3}, \mathrm{PbCO}_{3}, \mathrm{ZnCO}_{3}$, dan $\mathrm{Cu}_{2}(\mathrm{OH})_{2} \mathrm{CO}_{3}$ [2].

Tembaga $(\mathrm{Cu})$ merupakan salah satu jenis logam berat yang dapat kita temui di alam. Umunya logam $\mathrm{Cu}$ berwarna kuning kemerahan (orange). Logam $\mathrm{Cu}$ memiliki titik didih yang tinggi, sekitar $2595^{\circ} \mathrm{C}$ dan titik leleh $1083^{\circ} \mathrm{C}$ (MSDS, 2013). Logam $\mathrm{Cu}$ merupakan salah satu logam dari golongan transisi IB, dengan nomor atom 29. Di dalam larutan, logam $\mathrm{Cu}$ dapat membentuk ion $\mathrm{Cu}^{2+}$ dengan jari-jari ion $0,96 \mathrm{~A}^{\circ}$. Logam ini dalam kadar yang melebihi ambang batas normal, dapat menyebabkan keracunan [3].

Salah satu metode yang dapat digunakan untuk menguji kandungan logam berat di dalam batuan adalah metode Atomic Absorption Spectrophotometry atau yang biasa dikenal dengan istilah AAS. Prinsip kerja alat ini adalah mendeteksi radiasi elektromagnetik dengan panjang gelombang tertentu yang dapat diserap oleh atom-atom unsur dalam nyala dan juga mendeteksi radiasi yang diteruskan. Rasio energi yang diserap dan diteruskan tersebut disebut sebagai absorbansi [4].

Sebelum suatu sampel batuan diuji dengan alat AAS, terlebih dahulu batuan harus didestruksi. Sampel batuan didekomposisi dengan penambahan asam oksidator, diantaranya $\mathrm{H}_{2} \mathrm{SO}_{4}$ dan $\mathrm{HNO}_{3}$. Destruksi merupakan tahap yang penting, karena dengan adanya proses ini dapat mengurangi kandungan-kandungan ion pengganggu yang mungkin ditemukan di dalam batuan. Terdapat dua macam metode destruksi, yaitu destruksi basah dan destruksi kering $[5]$.

Destruksi merupakan suatu perlakuan untuk melarutkan atau mengubah sampel menjadi bentuk materi yang dapat diukur sehingga kandungan berupa unsur-unsur di dalamnya dapat dianalisis. Pada dasarnya ada dua jenis destruksi yang dikenal, yaitu destruksi basah dan destruksi kering, yang masing-masing mempunyai keunggulan dan kelemahan.

Destruksi kering merupakan perombakan organik logam di dalam sampel menjadi logam-logam anorganik dengan jalan pengabuan sampel dalam muffle furnace dan memerlukan suhu pemanasan tertentu. Destruksi basah adalah perombakan sampel dengan asam-asam kuat baik tunggal maupun campuran, kemudian dioksidasi dengan menggunakan zat oksidator. Pelarut-pelarut yang dapat digunakan untuk destruksi basah antara lain asam nitrat $\left(\mathrm{HNO}_{3}\right)$, asam sulfat $\left(\mathrm{H}_{2} \mathrm{SO}_{4}\right)$, asam perklorat $\left(\mathrm{HClO}_{4}\right)$, dan asam klorida $(\mathrm{HCl})$.

\section{METODE PENELITIAN}

\section{A. Alat dan Bahan}

Beberapa alat yang digunakan dalam penelitian ini adalah alat FAAS (Flame Atomic Absorption Spectrophotometry) Shimadzu AA 6800, mortar dan alu, ayakan mesh, kaca arloji , neraca analitik, spatula, erlenmeyer, hot plate, corong, labu ukur, botol semprot, pipet tetes, botol vial, botol timbang, gelas kimia, penghisap, pipet volume, pipet ukur, buret, statif dan klem, magnetic stirrer. Adapun bahan yang digunakan dalam penelitian adalah sampel batuan, aquademineralisasi, $\mathrm{Cu}\left(\mathrm{NO}_{3}\right)_{2} .3 \mathrm{H}_{2} \mathrm{O}, \mathrm{HNO}_{3}$ pekat.

\section{B. Pembuatan Larutan Standar Cu 1000 ppm}

Sebanyak 1,9011 gram $\mathrm{Cu}\left(\mathrm{NO}_{3}\right)_{2} .3 \mathrm{H}_{2} \mathrm{O}$ ditimbang dalam botol timbang menggunakan neraca analitik. Kemudian dilarutkan menggunakan aquademineralisasi dalam gelas kimia, masukkan ke dalam labu ukur $100 \mathrm{~mL}$ dengan 
bantuan corong. Gelas kimia dan labu ukur dibilas dengan aquademineralisasi secukupnya. Tambahkan $1 \mathrm{~mL} \mathrm{HNO}_{3}$ pekat dan ditambahkan aquademineralisasi sampai tanda batas.

\section{Destruksi Sampel Batuan Mineral}

Sampel batuan yang telah diayak dan dihaluskan, ditimbang sebanyak 0,5053 gram dalam gelas arloji menggunakan neraca analitik. Sampel batuan yang telah ditimbang, dimasukkan ke dalam erlenmeyer $100 \mathrm{~mL}$ yang telah dicuci dengan $\mathrm{HNO}_{3}$ pekat. Sebanyak $50 \mathrm{~mL} \mathrm{HNO}_{3}$ pekat ditambahkan sedikit demi sedikit ke dalam erlenmeyer untuk dilakukan destruksi basah.

Campuran tersebut dipanaskan di atas hot plate dengan kenaikan suhu secara perlahan-lahan hingga mencapai suhu $200^{\circ} \mathrm{C}$ dengan pengadukan menggunakan magnetic stirrer hingga warna campuran jernih dan konstan. Setelah warna campuran konstan, erlenmeyer diangkat dari hot plate dan didinginkan. Campuran yang telah dingin diencerkan menggunakan aquademineralisasi hingga volume $\pm 80 \mathrm{~mL}$ dan disaring menggunakan kertas saring Whatman dengan filtrat yang ditampung dalam labu ukur $100 \mathrm{~mL}$. Larutan yang didapatkan diencerkan dengan aquademineralisasi sampai tanda batas labu ukur.

\section{Pengenceran Larutan Stock Sampel}

Dilakukan pengenceran 100 kali larutan stock sampel. Larutan stock sampel dipipet sebanyak $1 \mathrm{~mL}$ dan dimasukkan labu ukur $100 \mathrm{~mL}$, kemudian diencerkan menggunakan aquademineralisasi sampai tanda batas labu ukur. Larutan dipindahkan dalam botol vial untuk penyimpanan.

\section{E. Pembuatan Larutan Standar Cu 100 ppm dan 10 ppm}

Pembuatan larutan standar $\mathrm{Cu} 100$ ppm dilakukan dengan memipet $10 \mathrm{~mL}$ larutan $\mathrm{Cu} 1000$ ppm, dimasukkan dalam labu ukur $100 \mathrm{~mL}$. Diencerkan dengan aquademineralisasi, ditambahkan $1 \mathrm{~mL} \mathrm{HNO}_{3}$ pekat, ditambahkan sampai tanda batas dengan aquademineralisasi.

Pembuatan larutan standar $\mathrm{Cu} 10$ ppm dilakukan dengan memipet $10 \mathrm{~mL}$ larutan $\mathrm{Cu} 100$ ppm, dimasukkan dalam labu ukur $100 \mathrm{~mL}$. Diencerkan dengan aquademineralisasi, ditambahkan $1 \mathrm{~mL} \quad \mathrm{HNO}_{3}$ pekat, ditambahkan aquademineralisasi sampai tanda batas.

\section{F. Pembuatan Larutan Standar Cu 8 ppm, 6 ppm, 4 ppm, 2 ppm}

Pembuatan larutan standar untuk kurva kalibrasi $\mathrm{Cu}$ dilakukan dengan cara memasukkan $20 \mathrm{~mL}, 15 \mathrm{~mL}, 10 \mathrm{~mL}$, dan $5 \mathrm{~mL}$ larutan $\mathrm{Cu} 10$ ppm ke dalam labu ukur $25 \mathrm{~mL}$ menggunakan bantuan buret. Diencerkan dengan aquademineralisasi, ditambahkan $1 \mathrm{~mL} \mathrm{HNO}_{3}$ pekat, dan pada akhirnya larutan ditambahkan aquademineralisasi sampai tanda batas, dikocok hingga larutan homogen.

\section{G. Pembuatan Kurva Kalibrasi Cu dan Penentuan Kadar Cu dalam Batuan Mineral}

Blanko yang berisi aquademineralisasi, larutan standar $\mathrm{Cu}$ yang telah dibuat serta larutan sampel $\mathrm{Cu}$ yang telah diencerkan 100 kali diukur absorbansinya pada panjang gelombang 324,7 nm dengan menggunakan instrumen FAAS
(Flame Atomic Absorption Spectrophotometry). Kurva dibuat dengan menghubungkan konsentrasi sebagai sumbu $\mathrm{x}$ dan absorbansi sebagai sumbu y sehingga didapatkan kurva linear sesuai persamaan $\mathrm{y}=\mathrm{mx} \pm \mathrm{c}$

\section{HASIL DAN DISKUSI}

\section{A. Destruksi Sampel Batuan}

Dipreparasi sebanyak 0.5 gram sample batuan yang telah dibuat serbuk dan telah diayak dengan metode destruksi basah. Proses destruksi sampel menghasilkan larutan berwarna biru jernih dengan adanya residu. Residu ini disaring menggunakan kertas saring.

Setelah proses destruksi berakhir, larutan didinginkan hingga tidak terasa panas sama sekali. Lalu, ditambahkan sedikit akuademin. Larutan hasil destruksi yang sudah dingin dipindahkan ke dalam labu ukur $100 \mathrm{~mL}$ untuk diencerkan dengan aquademineralisasi hingga tanda batas. Pengenceran 100 kali larutan stock sampel ini dilakukan dengan tujuan agar konsentrasi $\mathrm{Cu}$ tidak terlalu besar saat diukur menggunakan FAAS.

\section{B. Pembuatan Larutan Standar Cu 1000 ppm}

Dilakukan penimbangan senyawa $\mathrm{Cu}\left(\mathrm{NO}_{3}\right)_{2} .3 \mathrm{H}_{2} \mathrm{O}$ kedalam botol timbang. Hal ini dikarenakan, senyawa tersebut bersifat higroskopis [3]. Fungsi penggunaan aquademineralisasi adalah sebagai media pelarut untuk melarutkan larutan standar $\mathrm{Cu} 1000$ ppm. $\mathrm{HNO}_{3}$ pekat ditambahkan dalam proses pelarutan agar larutan dapat bertahan lama dan tidak rusak ketika penyimpanan.

\section{Pembuatan Kurva Kalibrasi $\mathrm{Cu}$}

Konsentrasi larutan $\mathrm{Cu}$ yang digunakan untuk pembuatan kurva kalibrasi adalah 2 ppm, 4 ppm, 6 ppm, 8 ppm, 10 ppm. Pembuatan larutan tersebut dilakukan pengenceran dengan aquademineralisasi dalam labu ukur $25 \mathrm{~mL}$ hingga tanda batas. Fungsi penggunaann aquademineralisasi ini adalah sebagai media pelarut untuk melarutkan semua larutan standar yang akan diukur absorbansinya. Pengukuran absorbansi larutan standar $\mathrm{Cu}$ menggunakan instrumen FAAS (Flame Atomic Absorption Spectrophotometry).

Tabel 1.

Hasil Pengukuran Absorbansi Larutan Standar Cu

\begin{tabular}{|c|c|}
\hline $\begin{array}{c}\text { Konsentrasi Larutan Standar Cu } \\
(\mathrm{ppm})\end{array}$ & Absorbansi \\
\hline 0 & 0,0009 \\
\hline 2 & 0,0818 \\
\hline 4 & 0,1512 \\
\hline 6 & 0,2366 \\
\hline 8 & 0,3072 \\
\hline 10 & 0,3884 \\
\hline
\end{tabular}

Berdasarkan data pengukuran absorbansi yang diperoleh maka dapat dilakukan pembuatan kurva kalibrasi dengan memplot konsentrasi $\mathrm{Cu}$ sebagai sumbu $\mathrm{x}$ terhadap nilai absorbansi sebagai sumbu $\mathrm{y}$, sehingga diperoleh kurva sebagai berikut : 


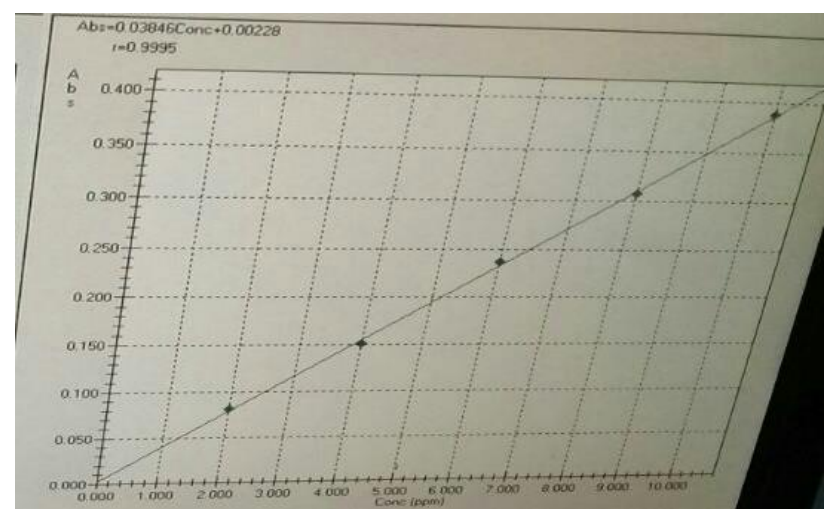

Gambar 1. Kurva Kalibrasi Larutan Standar $\mathrm{Cu}$

\section{Hasil Perhitungan Kadar Tembaga (Cu)}

Larutan destruksi yang telah terbaca absorbansinya pada panjang gelombang $324,7 \mathrm{~nm}$ memberikan data absorbansi seperti pada Gambar 1. Nilai absorbansi sampel pengenceran 100 kali yang tertera pada FAAS disubstitusikan pada persamaan $\mathrm{y}=0.03846 \mathrm{x}+0.00228$ maka didapatkan data berikut :

Tabel 1.

Konsentrasi $\mathrm{Cu}$ dalam ppm

\begin{tabular}{cc}
\hline \hline Absorbansi & Konsentrasi (ppm) \\
\hline 0.5311 & 13.7499 \\
0.4171 & 10.7858 \\
0.4155 & 10.7441 \\
0.4144 & 9.8345 \\
0.4267 & 10.1313 \\
0.4221 & 10.0203 \\
0.4085 & 10.9095 \\
0.4194 & 11.2067 \\
0.4123 & 11.0131 \\
\hline \hline
\end{tabular}

Untuk menghitung kadar $\mathrm{Cu}$ dalam batuan ini, maka konsentrasi yang didapat tersebut harus dikalikan dengan faktor pengenceran yakni $100 \mathrm{kali}$, dibagi dengan massa sampel batuan mineral yang ditimbang, kemudian dikalikan $100 \%$ sehingga dari percobaan ini didapatkan kadar tembaga (Cu) dalam sampel batuan mineral sebagai berikut :

Tabel 2.

Kadar $\mathrm{Cu}($ dalam \%) dalam sample

\begin{tabular}{cc}
\hline \hline Konsentrasi (ppm) & $\operatorname{Kadar}(\%)$ \\
\hline 13.7499 & 27.52 \\
10.7858 & 21.58 \\
10.7441 & 21.50 \\
9.8345 & 19.68 \\
10.1313 & 20.27 \\
10.0203 & 20.05 \\
10.9095 & 21.83 \\
11.2067 & 22.43 \\
11.0131 & 22.04 \\
\hline \hline
\end{tabular}

\section{E. Uji ANOVA (Analysis of Variance) Single Factor}

Dari data kadar yang dihasilkan 3 kelompok yang berbeda tersebut, dilakukan uji ANOVA One-Way untuk menguji apakah terdapat perbedaan yang signifikan antara data kadar yang dihasilkan oleh 3 kelompok tersebut. Dengan menggunakan Data Analysis Excel didapatkan hasil sebagai berikut :

Tabel 3.

Uji ANOVA One-Way

Anova: Single Factor

SUMMARY

\begin{tabular}{|c|c|c|c|c|c|c|}
\hline \multicolumn{2}{|c|}{ Groups } & \multicolumn{2}{|r|}{ Count } & Sum & Average & Variance \\
\hline \multicolumn{2}{|c|}{ Kelompok 16} & & 3 & 70.6 & 23.53333 & 11.92173 \\
\hline \multicolumn{2}{|c|}{ Kelompok 18} & & 3 & 60 & 20 & 0.0889 \\
\hline \multicolumn{2}{|c|}{ Kelompok 17} & & 3 & 66.3 & 22.1 & 0.0927 \\
\hline \multicolumn{7}{|l|}{ ANOVA } \\
\hline \multicolumn{7}{|l|}{$\begin{array}{c}\text { Source of } \\
\text { Variatio }\end{array}$} \\
\hline$n$ & $S S$ & $d f$ & $M S$ & $F$ & $P$-value & $F$ crit \\
\hline Between & 18.9488 & & 9.47444 & 2.34838 & 0.1764 & 5.14325 \\
\hline Groups & 9 & 2 & 4 & 9 & 8 & 3 \\
\hline Within & 24.2066 & & 4.03444 & & & \\
\hline \multirow[t]{2}{*}{ Groups } & 7 & 6 & 4 & & & \\
\hline & 43.1555 & & & & & \\
\hline Total & 6 & 8 & & & & \\
\hline
\end{tabular}

Dari uji ANOVA tersebut, terlihat bahwa Fhitung (2.348389) < Fkritis (5.143253) maka data kadar dari ketiga kelompok tersebut tidak terdapat perbedaan yang signifikan.

\section{F. Uji Grubbs}

Dari ke-9 data kadar $\mathrm{Cu}$ yang didapat dilakukan uji G(Grubbs) karena terdapat 1 data yang berbeda jauh dari data-data yang lain didapatkan data berikut :

$$
\begin{gathered}
\text { Tabel } 4 . \\
\text { Uji Grubbs }
\end{gathered}
$$

\begin{tabular}{rrrr}
\hline \hline Standar Deviasi & UJI G hitung & G Tabel & Kadar Rerata(\%) \\
\hline 2.320505352 & 2.43 & 2.215 & 21.17 \\
\hline \hline
\end{tabular}

Karena $\mathrm{G}_{\text {hitung }}>\mathrm{G}_{\text {tabel }}$, maka data yang berbeda jauh tersebut dapat dihilangkan, maka didapatkan hasil kadar $\mathrm{Cu}$ sebesar $21.17 \%$

\section{KESIMPULAN/RINGKASAN}

Berdasarkan percobaan yang telah dilakukan didapatkan persamaan kurva regresi standar y $=0.03846 \mathrm{x}+0.00228$ dengan $\mathrm{R}=0.9995$, serta didapatkan bahwa kadar logam $\mathrm{Cu}$ yang terkandung dalam sampel batu sebesar $21,17 \%$ berat.

\section{DAFTAR PUSTAKA}

A. Smith, Pustaka Sains Material. London: Usborne Publishing Ltd, 2001.

[2] B. K. Tambunan, "Penentuan Kadar Ag, Cu, dan Fe di Dalam Batuan Mineral yang Berasal dari Dusun Jambu Dolok Kabupaten Toba Samosir," Universitas Sumatera Utara, 2013. 
[3] "MSDS," 2017. [Online]. Available: www.sciencelab.com.

[4] S. P. D. Kunti, "Kemampuan Adsorspi Batu Pasir yang Dilapisi Besi Oksida ( $\mathrm{Fe} 2 \mathrm{O} 3$ ) untuk Menurunkan Kadar $\mathrm{Pb}$ dalam Larutan," J. Bumi Lestari, vol. 9, no. 2, pp. 254-262, 2009.

[5] K. Susila, "Kajian Berbagai Proses Destruksi Sampel dan Efeknya," in Prosiding Seminar Nasional Penelitian, Pendidikan dan Penerapan MIPA Yogyakarta, 2012, p. K-195K-202. 